\title{
Retreatment and Conservation of a Wooden Panel Previously Treated With Bees Wax
}

\author{
Nesrin Mohamed Nabil El Hadidi a , Hamdy Abdel-Monem b ${ }^{\text {, Mourad }}$ \\ Fawzy Mohamed ${ }^{\text {a }}$, Ghada Gamal Hashem ${ }^{\mathrm{c} *}$ \\ a. Conservation Department, Faculty of Archaeology, Cairo University, Giza, Egypt \\ b. G.M of Conservation Department, Museum of Islamic Art \\ c. MA student, Conservation Department, Faculty of Archaeology, Cairo University, Giza, Egypt
}

\section{HIGHLIGHTS}

- The process of retreatment of a wooden panel at the Islamic Museum of Art in Cairo was preceded by an experimental study on the effects of bees wax on wood.

- Bees wax samples and pine samples treated with wax were exposed to direct and indirect sunlight for 50 consecutive days to study the initial effects of deterioration.

- For assessment of deterioration USB digital microscope images, color change measurements and FTIR spectroscopy were used.

\section{ARTICLE INFO}

\section{Article History:}

Received: 27 June 2020

Revised: 25 November 2020

Accepted: 16 December 2020

Available online: 21 December 2020

Keywords:

Retreatment, Bees wax, Color Change, FTIR, Wooden Panel

\footnotetext{
* Corresponding author: ghadagamal2017@yahoo.com
}

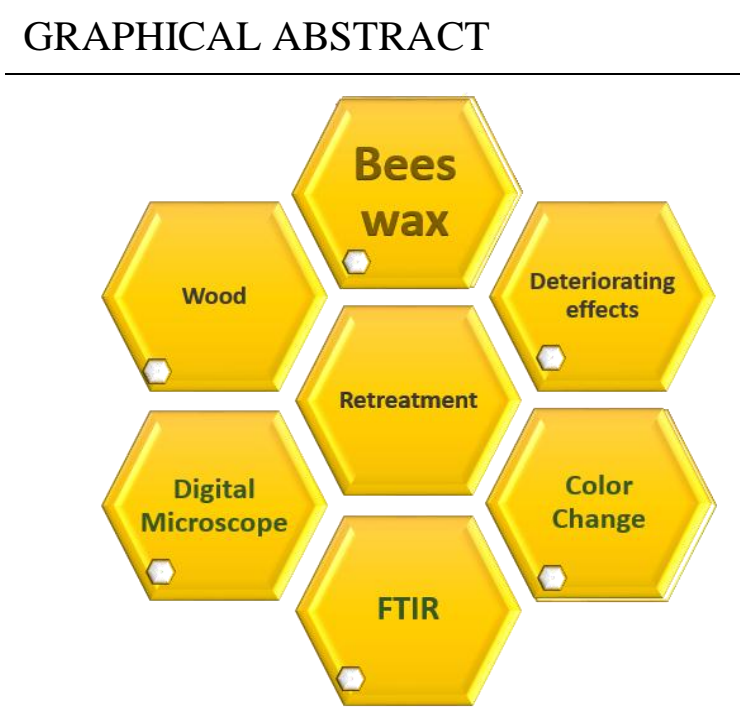

\begin{abstract}
The aim of this research is to study the deteriorating effect of bees wax, which was a commonly used conservation/restoration material in archaeological wooden artifacts. An experimental study was conducted, in which bees wax was applied on pine wood samples and aged by exposure to direct and indirect sunlight during the months of Mai and June in Giza/ Egypt for 50 consecutive days, when the average temperature was around $40^{\circ} \mathrm{C}$ during the day. Discs of bees wax were exposed to the same ageing conditions. The surface of all samples was examined using a digital USB microscope, color change was measured and FTIR spectroscopy was conducted to assess the changes that occur in both wood and bees wax,
\end{abstract}


in order to determine the deteriorating effect of wax on wood directly after application and after exposure to direct and indirect sunlight. After obtaining the results from the experimental study, in which it was concluded that wax has a deteriorating effect on wood; a wooden panel in the museum of Islamic Art in Cairo, which had been mainly treated with bees wax in the past, was chosen for the applied part of this research. The panel was carefully documented before taking the decision to remove previous treatments prior to the retreatment using microcrystalline cellulose and Klucel G.

\section{Introduction}

When museums opened to the public in Egypt more than one hundred years ago, it was mainly archaeologists or curators who would treat an artifact to the best of their knowledge. Restoration and conservation of archaeological wooden objects was conducted according to restoration trends that depended heavily on using materials that were available at the time. Many artifacts were maintained back then, but a few objects have deteriorated, due to insufficient awareness and knowledge about conservation materials. There are examples of previous treatments that have had a negative impact on artifacts leading to the complete destruction of objects. Some of these examples include artifacts that perished shortly after their consolidation in the past; because the material had penetrated inside the voids or cells of organic materials and caused total disintegration, due to chemical reactions between the material of the artifact and the treatment materials.

In many cases the restoration materials were mainly the same materials that were used in the making of an artifact, such as beeswax or animal glue. Therefore it may seem very confusing to think that these materials are often considered an unacceptable conservation material, and conservators opt to remove them from an artifact to replace them with "new materials". Yet there are many reasons for taking a decision to "retreat" an artifact, for instance; the layers of wax are extremely thick or the treatment material is a cause of chemical disintegration .

The removal of consolidants, adhesives and coating materials is a sophisticated process that depends on the solubility of the materials after so many years of their application and the state of preservation of the wood. It is also a process which may have some drawbacks, if the wrong procedure is executed. There are two main options for removing previous restoration materials; namely mechanical and chemical cleaning methods. Chemical cleaning techniques can be further divided into traditional and novel materials and methods .

Traditional materials and methods in chemical cleaning include organic solvents, acids and alkalis; and researchers have evaluated their effect on wood components indicating that the degrading effect of polar and nonpolar organic solvents in removing old restorations is minimal. Toluene for example is a non-polar solvent that showed a slight change in the chemical composition of wood compared to other solvents [1], [2], whereas ethyl alcohol at a concentration of $80 \%$ is the best polar solvent and has the least degrading effect on the chemical composition of the wood compared with other commonly used solvents, such as acetone [1-3]. Acids and alkalis should be the last resort, because their chemical effect on wood components cannot be prevented [1], [3].

Novel materials and methods, such as gelled systems are used in cases, where wooden objects had been treated with polymers that are difficult to remove with traditional materials. These systems are capable of retaining the liquid compound, which prevent it from spreading and avoid any mechanical stress during the removal process [4]. Gels are divided into two major categories: physical and chemical gels. Previous studies proved that the chemical gel is more efficient in the removal process and no gel residues are left behind on the surface at the end of the process, because it has a strong gel cohesion [4], [5], on the contrary to the physical gel, which leaves residues on the surface and needs to be removed with organic solvents [6].

Currently there are several options that could be chosen for the removal of old treatments. Any technique has its advantages and disadvantages, which makes it difficult to decide 
how an old treatment is to be removed. Therefore, it has become necessary to apply a certain strategy every time an object is being retreated, and the preliminary step is to put several issues into consideration, such as:

1 - Which restoration material was used in the past?

2- How was the treatment applied in the past?

3- Has the old treatment material affected the authenticity of the artifact?

4- What kind of impact would the removal of the old treatment have on the strength of the object?

5- Can it be replaced with a new material?

Old treatments can be extremely tricky to remove, without causing harm to the artifact, especially the surface. There are many restoration materials that had been used in the past, but in this paper the investigations and analysis that were carried out on experimental samples were limited within bees wax, which was identified as a restoration material that had been applied on a previously treated wooden panel (register number 11618) in the storage of the Islamic Museum of Art in Cairo. The aim of this paper is to study the deteriorating effect of bees wax that had been commonly applied on archeological wood in the past, in order to decide whether or not to remove it prior to the retreatment of the artifact.

\section{Old restorations at the Islamic Mu- seum of Art in Cairo}

Khedive Tewfik gave the decree that led to the establishment of the Museum of Arab Art in 1881, in which it authorized a group of European and Egyptian art preservationists, led by the Hungarian architect and conservator Max Herz, to gather detached fragments from historic structures in Cairo that had fallen into disrepair [7]. At that time most of the ancient monuments were being reused, causing a lot of loss of architectural elements such as the conversion of the Mosque of AlNasir Mohammad Ibn Qalawun into a prison and a military store in 1882 [8].

The large collection of wooden objects at the Islamic Museum of Art in Cairo had been treated with a lot of different materials over the decades. One of the most commonly identified materials that were used in the treatment of objects at the museum was bees wax.

Natural or bleached bees wax is one of the oldest materials that were used in wood restoration as filler, adhesive and consolidant; which was necessary to maintain the integrity of wooden artifacts. It is commonly found in the form of either small or large amounts on wooden objects at the Egyptian Museum in Tahrir [9] and at the Museum of Islamic Art.

Different application techniques were practiced throughout the history of conservation, resulting in different deterioration effects on archaeological wood. Wax can cause an increase in wood weight, leave a greasy appearance on wood, increase dust attraction and cause darkening of the wood surface [10], but the most deteriorating effect is the acidity of beeswax and colophony mixture and the use of heat during its application on wood. Studying the penetration of bees wax using scanning electron microscope [11] could be used in future studies to understand how wood cell walls are affected, but this was beyond the scope of this paper.

\section{Materials and Methods:}

Bees wax was purchased from "Ragab El Atar" (a chain of shops that specializes in selling herbs, spices and natural products in Egypt). It had to be purified by melting the wax in distilled water followed by exposure to the sun for 7 days [12]. For the experimental part the following samples were prepared:

a- Molten wax was poured in small Petri dishes and left to harden in the form of a disc.

b- Samples of pine wood were treated by brushing the wood with molten wax.

\subsection{Aging of bees wax samples}

Due to the low melting point of bees wax, it was not possible to age the samples according to some of the commonly applied standards such as Standard Specification for Aging: Standard for wood pulp paper BS 63883:1996 - ISO 5630-3:1996, Paper and boardAccelerated ageing; moist heat treatment at $80^{\circ} \mathrm{C}$ and $65 \%$ relative humidity, where the 
period of exposure is 120 hours continuous, which is an equivalent of 25 years in normal conditions [13], [14], [15], because samples would simply melt. Therefore both bees wax discs and wood samples that had been treated with bees wax were aged by exposure to direct sunlight for 50 consecutive days during the summer months (May/June 2019) in Giza, Egypt, when the average temperature was around $40^{\circ} \mathrm{C}$ and $\mathrm{UV}$ index was high during the whole afternoon on a daily bases. Relative humidity was below $20 \%$ during the day and at around dawn it reached an average of $65 \%$. During the 50 days sunrise was at around 5.00 am and sunset at around 6.50 pm. All samples were exposed to sunlight and heat from sunrise till sunset. The samples that were exposed to direct sunlight remained uncovered during the whole period, while samples that were exposed to indirect sunlight remained inside a cardboard box, to prevent any light from reaching the samples.

\subsection{USB Digital Microscope}

Model; USB S02, Cooling Tech 50X to 500X optical zoom

\subsection{Color change measurements:}

Color change was measured with Optimatch 3100® SDL Company using the CIE lab system.

\subsection{FTIR analysis}

FTIR analyses were measured with a Nicolet 380 at the National Center for Measurement and Calibration, Giza, Egypt. The frequency range was $4000-400 \mathrm{~cm}^{-1}$ in transmission mode using $\mathrm{KBr}$ pellet technique. Peak heights and width of absorption bands were measured by Essential FTIR software (version 350- 071).

\section{Results and discussion}

\subsection{USB Digital Microscope Examination} 4.1.1. Bees wax disc

In the images taken by the USB digital microscope (Fig.1) the unexposed bees wax sample (a) was compared with the aged samples; yellowness occurred in the sample that was exposed to indirect sunlight (b) and darkening in the sample that was exposed to direct sunlight (c) was noticeable. There are presumably two reasons for the darkening of the wax samples;

1- During natural ageing of waxes, basic mechanisms of degradation of individual components such as hydrolysis and oxidation take place [16].

2- The bees wax samples that had remained uncovered during the whole period of exposure attracted dust from the air.

\subsubsection{Wood samples consolidated with bees wax}

By comparing the images taken by the digital microscope of wood sample before and after treatment with wax (Fig. 1), it is clear that the wax had covered the wood surface and did not penetrate the wood cells giving a greasy appearance and a blurry image $(\mathrm{d} \&$ e). After exposure to indirect sunlight (f), the heat caused softening of the wax and slight color change to the wood sample, but after direct sunlight exposure (g) the soft wax attracted dust and the surface of the wooden sample darkened.

\subsection{Color change measurements}

After exposing the bees wax discs to both indirect and direct sunlight a remarkably high color change was recorded in both cases (Table 1). In the wood samples that had been treated with wax the wood slightly darkened after application, but after indirect sunlight exposure color change was almost negligible. After direct sunlight exposure the color change was extremely high due to the dust particles that had adhered to the treated wood surface.

\subsection{FTIR analysis}

FTIR spectra of bees wax discs before and after exposure to direct and indirect sunlight were compared (Fig. 2). A decrease in $\mathrm{OH}$ stretching as a result of loss in the moisture content after direct and indirect exposure and an increase in $\mathrm{C}=\mathrm{O}$ in $1720 \mathrm{~cm}^{-1}$ in the bees wax sample after exposure to direct sunlight (sample 2), resulting in yellowness of the sample occurred. These changes may be an indication of splitting of ester groups, and the formation of free acids and oxidative effects 
[17], and the number of carboxyl groups increases with the increasing number of degradation products resulting from oxidation degradation products [16].

After treating the pine wood sample with bees wax (Fig. 3a) decrease in $\mathrm{OH}$ stretching as a result of loss in the moisture content after treatment and decrease in $\mathrm{C}=\mathrm{O}$ at 1735 $\mathrm{cm}^{-1}$ as a result of loss of hemicellulose after treatment occurred. The wax treated pine wood samples that were exposed to indirect sunlight (Fig. 3b) and direct sunlight (Fig. 3c) also showed a clear decrease in $\mathrm{OH}$ stretching as a result of loss the moisture content after treatment and decrease in $\mathrm{C}=\mathrm{O}$ at $1735 \mathrm{~cm}^{-1}$ as a result of loss of hemicellulose after treatment. Wax treatment and exposure to sunlight, both direct and indirect, affected the main wood bands, but at different rates.

By comparing the ratio of intensities in the FTIR spectra within each sample separately of the non-aged pine wood, the three nonaged and aged wood samples that were treated with beeswax according to the peak heights of the main lignin band at $1508 \mathrm{~cm}^{-1}$, the hemicellulose band at $1735 \mathrm{~cm}^{-1}$ and the three cellulose bands at $1425 \mathrm{~cm}^{-1}, 1375 \mathrm{~cm}^{-1}$ and $897 \mathrm{~cm}^{-1}$ interesting [18] results were obtained (Fig. 4). The ratio between lignin and the band at the $\mathrm{CH}_{2}$ bending cellulose (crystallized I and amorphous) at $1425 \mathrm{~cm}^{-1}$ was almost the same in the sample that was exposed to direct sunlight, decreased in the non-aged sample treated with wax, and increased in the sample that was exposed to indirect sunlight. A very clear decrease of ratio between the intensity of lignin and both cellulose bands at $1375 \mathrm{~cm}^{-1}$ and $897 \mathrm{~cm}^{-1}$ was calculated in all the wood samples that were treated with bees wax, which indicates that the addition of bees wax caused an increase in cellulose band relative to lignin, or in other words the wood lignin was more affected by the wax treatment. After direct and indirect sunlight exposure of the wax treated samples the main carbohydrate bands, with the exception of the band at $1425 \mathrm{~cm}^{-1}$, the $\mathrm{CH}_{2}$ bending cellulose in the sample that was exposed to indirect sunlight, showed a decrease in ratio, confirming that lignin was mainly affected by the wax.
With the above mentioned results and results from recently published research, which concluded that "rather unexpected results might indicate a higher sensitivity of waxes to visible light compared to UV light" [17] it was necessary to take a decision in the retreatment of a wooden panel at the Islamic Museum of Art. It seemed obvious that the wax from old restorations needed to be removed, before any further treatments were to be applied.

\section{Removal methods of bees wax}

On the contrary to the experimental pine wood samples that are less porous than archaeological wood in artifacts, wax easily penetrates the wood voids during treatment of decayed wood, which explains why the wax in previous treatments has now become part of the wooden structure. Complete removal of old wax treatments may have a deteriorating effect; therefore the best option to preserve the wooden object is to stabilize it (whether it had been treated with either pure wax or a mixture of wax and colophony, which was common).

The deteriorating effect of bees wax on archaeological wood has forced conservators to find methods to remove old wax restorations which are based on:

- The state of the wooden object.

- The amount of wax that had been added to the object.

- The original reason for using wax; i.e. as consolidant, adhesive or filler material.

Removing wax that was used as consolidant material is a difficult process, because it does not only depend on the state of preservation of the object, but also on the application methods, materials which were added to the wax such as colophony and if any polymers had been used as coating materials i.e. Paraloid 72 or PVA emulsions. The past application methods and current removal techniques are summarized in Table 2.

If a wooden artifact needs reconsolidation after removing the wax, it is preferable to use materials that can be easily dissolved in organic solvents; but if water soluble materials are chosen, it is necessary to wait around 48 72 hours after completing the wax removal process. 

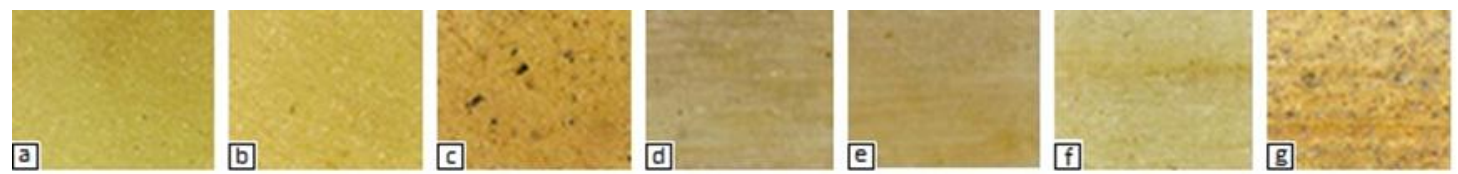

Fig. 1. Comparison between samples (a) bees wax before exposure, (b) bees wax after indirect sunlight exposure, (c) bees wax after direct sunlight exposure. (d) untreated wood, (e) wood after bees wax application, (f) bees wax treated wood after indirect sunlight exposure, $(\mathrm{g})$ bees wax treated wood after direct sunlight exposure.

Table 1. Color change measurement of bees wax samples

\begin{tabular}{l|c|c|c|c}
\hline \multicolumn{1}{c|}{ Sample } & $\mathrm{L}^{*}$ & $\mathrm{a}^{*}$ & $\mathrm{~b}^{*}$ & $\Delta \boldsymbol{E}$ \\
\hline Bees wax disc (standard) & 23.44 & 2.11 & 9.89 & - \\
\hline indirect sunlight exposure & 22.14 & 2.68 & 5.85 & 8.40 \\
\hline direct sunlight exposure & 22.70 & 3.32 & 3.94 & 9.02 \\
\hline Pine wood sample (standard) & 73.78 & 4.34 & 19.01 & - \\
\hline after wax application & 68.90 & 5.28 & 23.02 & 4.27 \\
\hline after indirect sunlight exposure & 66.97 & 5.63 & 22.87 & 1.57 \\
\hline after direct sunlight exposure & 38.56 & 9.11 & 14.36 & 30.24 \\
\hline
\end{tabular}

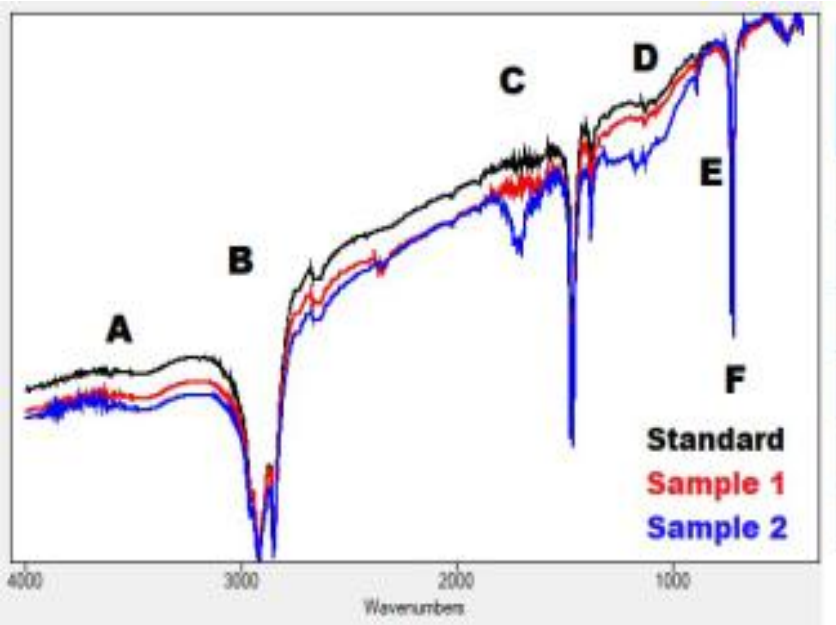

\begin{tabular}{|c|c|c|}
\hline N. & $\begin{array}{c}\text { Wavenumber } \\
\left(\mathrm{cm}^{-1}\right)\end{array}$ & $\begin{array}{c}\text { Functional group } \\
\text { bands }\end{array}$ \\
\hline A & $3200: 3600$ & OH stretching \\
\hline B & $2800: 3000$ & C-H stretching \\
\hline C & $1700: 1750$ & C=O stretching \\
\hline D & $1300: 1480$ & $\mathrm{C}=\mathbf{O}$ stretching \\
\hline E & $900: 1300$ & $\mathrm{C}=\mathrm{C}$ stretching \\
\hline F & $\mathbf{7 0 0 : 7 5 0}$ & $\mathrm{CH}_{2}$ bending \\
\hline
\end{tabular}

Fig. 2. FTIR spectra of non-aged bees wax (standard), sample 1 (after indirect sunlight exposure) and sample 2 (after direct sunlight exposure) 


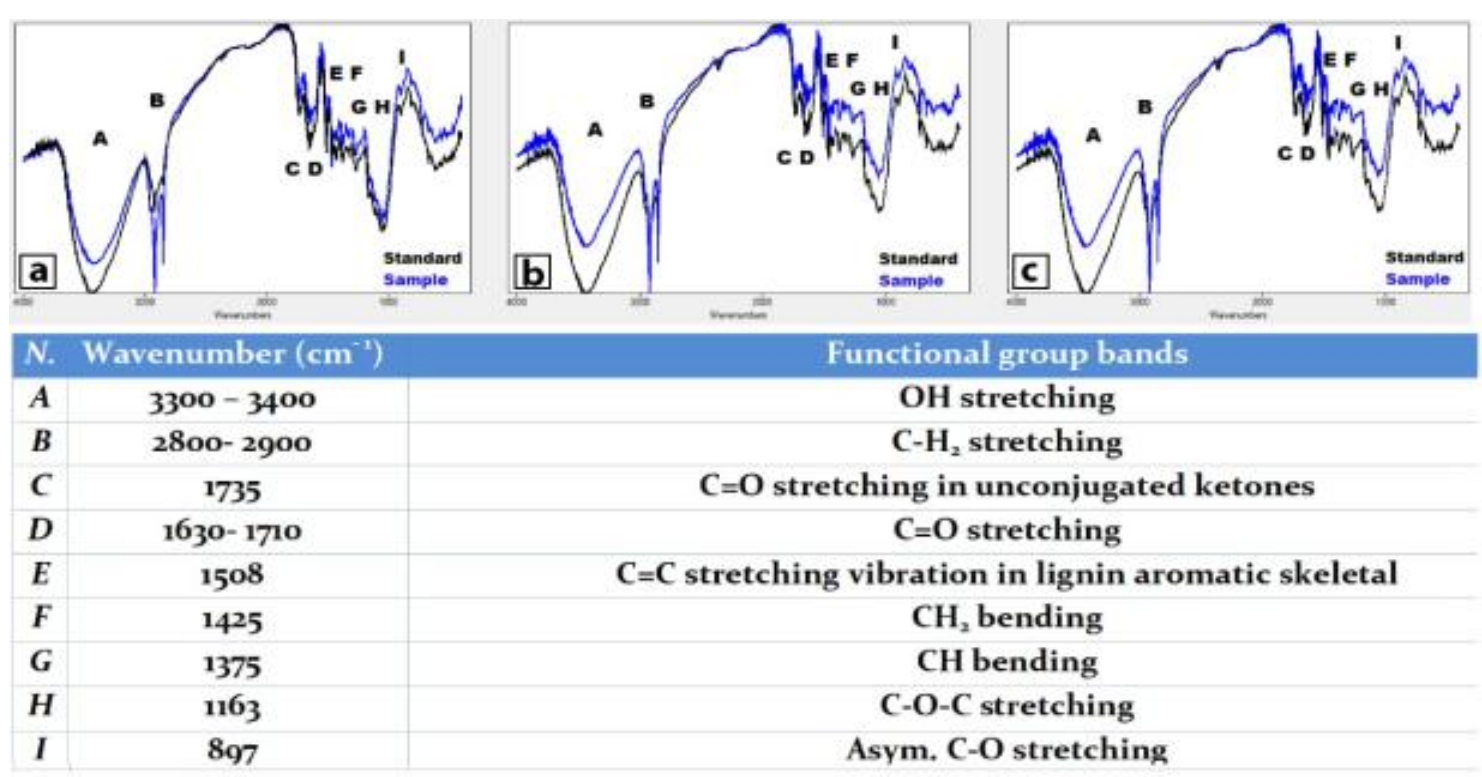

Fig. 3. FTIR spectra of pine wood samples (a) before wax treatment (standard) and after wax treatment (sample) - (b) exposed to indirect sunlight, pine wood (standard) and pine wood treated with wax (sample) - (c) exposed to direct sunlight, pine wood (standard) and pine wood treated with wax (sample)

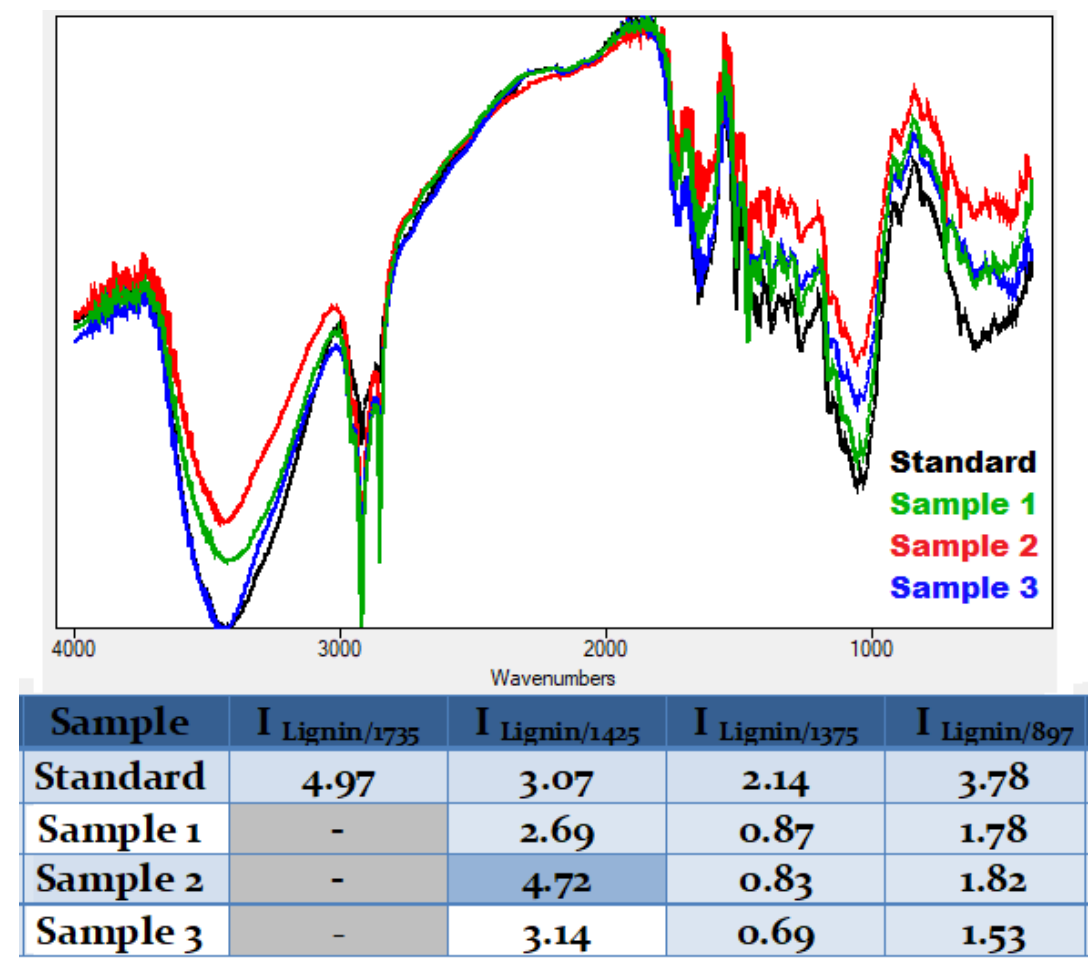

Fig. 4. Calculations of ratios between the lignin and carbohydrate bands within each sample separately, indicating the effect of bees wax on non-aged wood sample prior to wax treatment (standard), the non-aged wood sample treated with wax (sample 1) the treated pine wood that was exposed to indirect sunlight (sample 2), the treated pine wood that was exposed to direct sunlight (sample 3). 
6. Retreatment a wooden panel in the storage at the Museum of Islamic of Art in Cairo:

Museums had a unique way of accomplishing conservation tasks in the past, and therefore a preliminary step would be to identify the most common materials and methods that were applied on any artifact, before attempting to retreat artifacts at a museum.

It is important to acknowledge that all the artifacts that we can hold in our hands today have been treated in the past with the aim to prevent deterioration. Therefore it is necessary for a conservator to acquire or collect as much information as possible about previous treatment techniques.

A pinewood panel, of unknown date and provenance, which had been acquired in 1933 in the storage of the Islamic Museum of Art in Cairo (register number 11618) was chosen as an example for retreatment. The panel consists of nine incised Kufic lines, five of them were colored black, yet there was no evidence of colors in the four other lines. It is possible that the artist applied the idea of interchange of colored and noncolored lines, where lines 1, 3, 5, 7 and 9 had been colored in black, yet currently only traces of the black color are visible to the naked eye. The Quran writings are Surat AlIkhlas, Alkursi verse, Alfatiha, Alnas, Alfalaq.

The panel was cracked and separated longitudinally into two parts; the larger part measured $32 \times 125 \mathrm{~cm}$ and the smaller part measured $20 \times 88 \mathrm{~cm}$. The total dimensions of the object are ca. $125 \times 39 \mathrm{~cm}$ (Fig. 5).

Examination and analysis were conduct to identify the materials which had been used in prior treatments. That was followed by choosing a suitable conservation strategy for removing the old conservation material and retreatment of the panel.

\subsection{Investigation and analysis:}

The panel was carefully documented using a Nikon D 700 digital camera and Auto Cad drawing. The surface was investigated using a digital USB microscope, and samples of previous conservation/restoration materials and wood were analyzed using FTIR spectroscopy.

For retreatment classical mechanical and chemical cleaning techniques were applied using scalpels, dental tools, cotton swabs/poultices, ethyl alcohol and toluene. To treat and straighten the deformed panel wooden sticks, non- stick paper and metal clamps were used. Gaps were refilled with a mixture of microcrystalline cellulose (a carbohydrate material manufactured by FMC Biopolymer) and sawdust of a pinewood (2:3) mixed with Klucel G dissolved in ethyl alcohol and water $(1: 1 \mathrm{v} / \mathrm{v})$ and wood was consolidated with Klucel $\mathrm{G}$ dissolved in ethyl alcohol.

\subsubsection{Visual assessment}

The object was suffering from darkening of color, dust, dirt, cracks, white paint inscriptions, warping, wood knots, wax and remains of adhesive. All types of deterioration were documented as in Fig. 6.

\subsubsection{Digital microscope}

The surface of the panel was scanned with a digital microscope, for the documentation of different decaying factors that were found in various parts of the panel. Fig. 7 shows a few examples of resulting visual effects of previous treatments. On the top right part of every figure a small image has been added to clarify the spot which was magnified with the digital microscope.

\subsubsection{Fourier-transform infrared spec- trometry (FTIR)}

Samples were taken of the adhesive and coating layer (Fig. 8a), the wax that had been used in the past treatments (Fig. 8b) and a flaking piece of wood of the panel (Fig. 8c). By comparing the functional groups of the first sample taken from the object with the standard functional groups of Paraloid B72 [25][26][27], it was confirmed that Paraloid B72 had been previously used for the treatment of the panel as an adhesive and coating layer. Paraloid B72 was a commonly used acrylic polymer that was applied as a consolidant and adhesive material in conservation 


\section{Table (2) Methods of bees wax application and current removal techniques} of wax

\begin{tabular}{l}
\hline Application Method in the Past \\
\hline 1. By melting the wax and \\
brushing it on the wood [19]. \\
2. Immersing the wood in a \\
bath containing a mixture of \\
bleached wax and colophony \\
(1:1) heated at $1^{\circ} \mathrm{C}$. After \\
treatment the wood is left to \\
dry in a slanting position, so \\
that excess wax drips off. \\
Any remains of wax on the \\
surface were cleaned with ei- \\
ther benzene or turpentine \\
[20][21].
\end{tabular}

3. Applying the mixture on wood with the aid of a hot soldering iron [22].

4. Brushing a mixture of $(1.5 \mathrm{~g}$ wax, $1.5 \mathrm{~g}$ colophony in $100 \mathrm{~cm}^{3}$ trichloroethylene) on the wood until it is totally saturated [23].

5. Using a mixture of beeswax and vegetable turpentine oil $1 / 5: 1$, which is heated and applied by brush until the wood is saturated [24].

\section{Current Removal Techniques}

Waxes used as adhesives or filler materials:

1. Scalpels or dental tools can be used to remove a wax layer until the wood surface is reached.

2. Wax remains are removed using cotton swabs soaked in non-polar organic solvents such as toluene, benzene or xylene, but it is advisable to opt for toluene due to its minimal degrading effect on wood.

3. Removing the thick layer of wax by using scalpels and dental tools.

Large amounts of wax:

1. Using swabs saturated with toluene to remove any remains of superficial wax and dust which cause surface darkening.

2. Storing or exhibiting the object in a controlled environment.

Small amounts of wax:

1. Swabs immersed in toluene are used to clean the surface of the wooden object and remove the surface layer of wax and any dust or dirt attached to it.

2. Brushing pure toluene directly on the wood to dissolve the wax that had penetrated the wood, and to facilitate wax extraction.

3. Using cotton compresses saturated with toluene helps in gradually extracting a large amount of the wax that had penetrated the wood.

Wax mixed with colophony:

1. Cleaning the surface layer of the wooden object with swabs saturated with toluene to remove the surface layer of wax and any dust or dirt.

2. Using a source of heat or hot air $\left(40-50{ }^{\circ} \mathrm{C}\right)$ softens the solid mixture of wax and colophony that had penetrated the wood. The softened wax is easily removed mechanically and with a small amount of solvent.

3. If the wood had been treated additionally with Paraloid B72 or any acrylic material, heat should not be applied for removing the wax and colophony, because exposure to heat softens Paraloid and spreads it further inside the wood and strengthens its cohesion to the cell walls. 

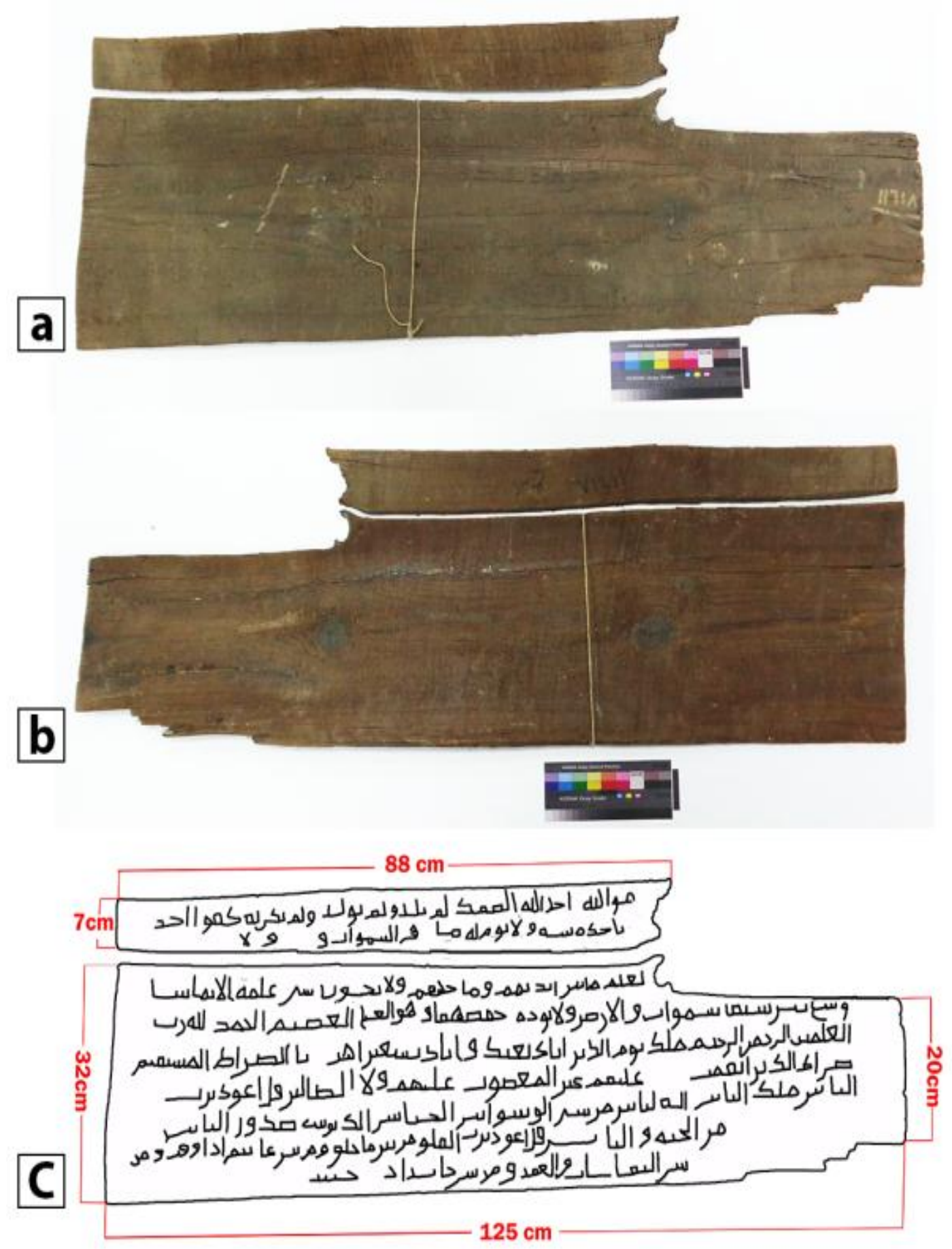

Fig. 5. (a) Front of the wooden panel, (b) Back of the wooden panel, (c) The dimensions and inscriptions of the wooden panel 

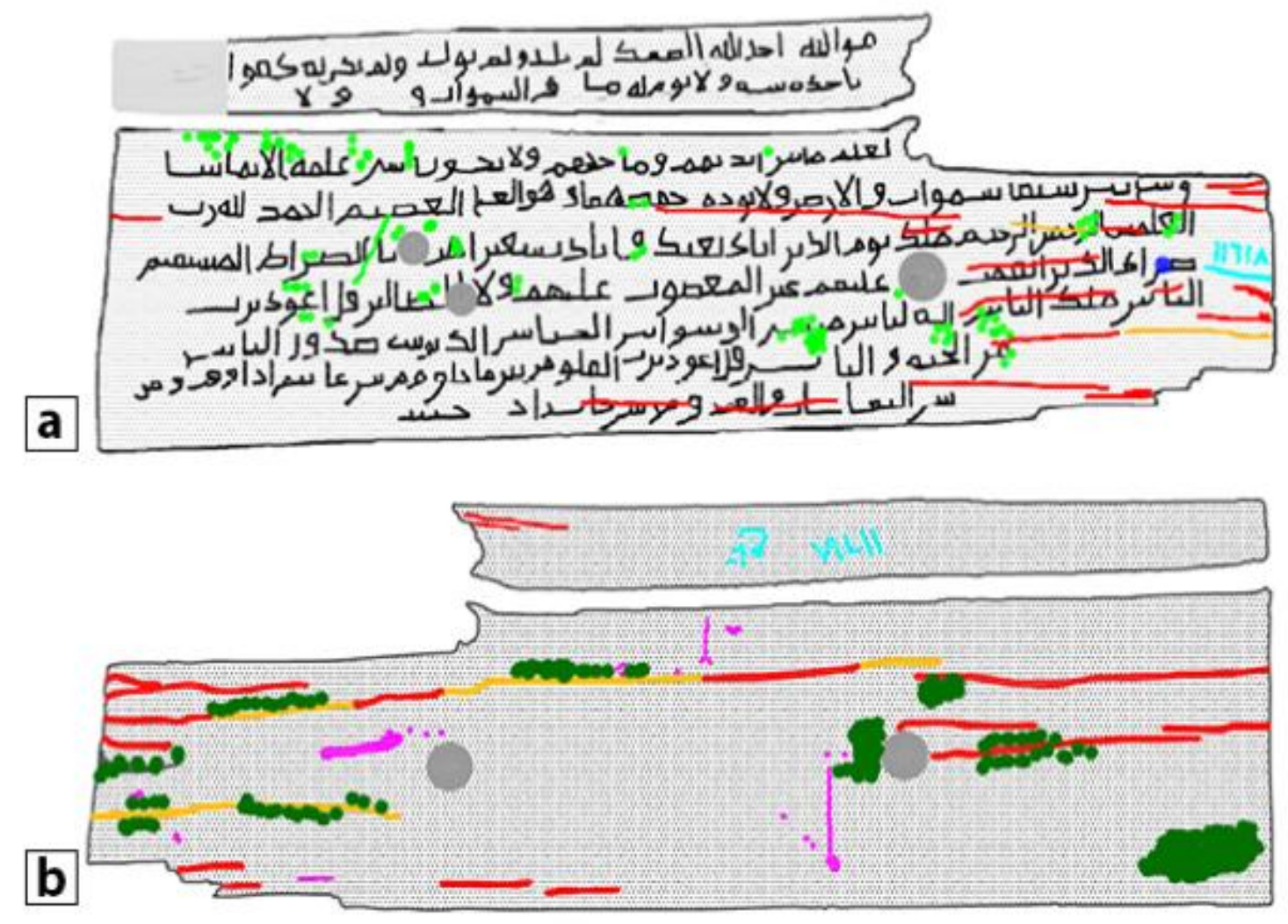

\begin{tabular}{|c|c|c|c|c|}
\hline Dust and wax remains & Cracks & Dirt and stains & Writings & Wood darkening \\
\hline Remains of adhesive & Wax & Color change & Metal nail & Wood knots \\
\hline
\end{tabular}

Fig. 6. Deterioration map of front (a) and back (b) of the wooden panel

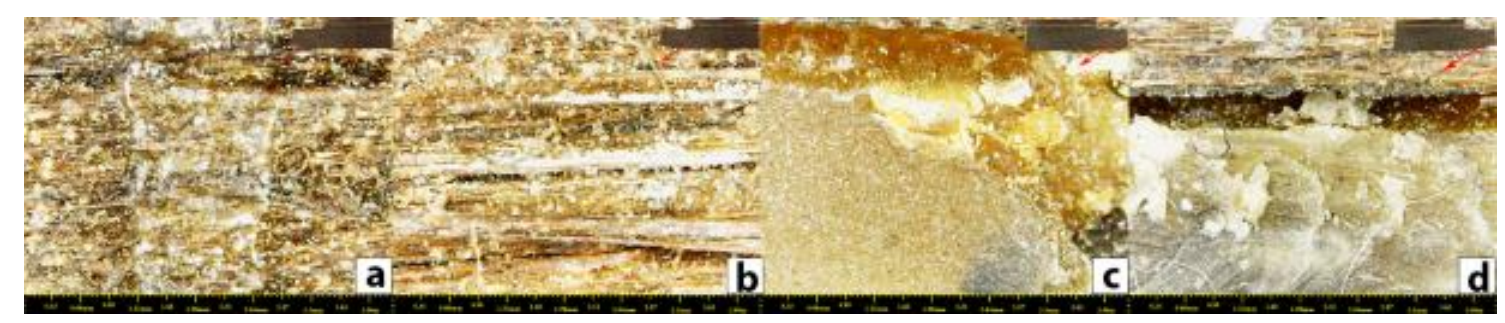

Fig. 7. Digital microscope examination of the wooden panel. (a \& b) deposition of Paraloid B72 on the wood surface, (c \& d) depostion of wax inside wood cracks 
[28][29], but its disadvantage is it's deteriorating effects on wooden objects such as darkening/ yellowing, it can be infested with microorganisms [30], and is an unstable material that deteriorates due to the occurrence of an oxidation process when exposed to UV [31][32].

By comparing the functional groups of the second sample taken from the object with the standard functional groups of bees wax [27][33] [34] [35], it was confirmed that bees wax was used to treat the panel in the past. Its disadvantages have been discussed in the experimental part of this paper.

In the FTIR spectra of the flaking wood sample a strong change was noticed in the increase of $\mathrm{C}=\mathrm{O}$ stretching band at $1641 \mathrm{~cm}^{-1}$ due to the oxidation of cellulose, and the decrease of moisture content of the wood in the panel [36]. The peak height of lignin at 1508 $\mathrm{cm}^{-1}$ was relatively small indicating loss of lignin in the panel, which was clear during handling of the panel, in which some parts gave the woolliness texture of wood.

By comparing the ratio of intensities in the FTIR spectra (Fig. 9) of the non-aged wood sample, the pine wood that was exposed to indirect sunlight, the pine wood that was exposed to direct sunlight and the archaeological sample taken from the panel, it is clear that the ratio of lignin and the three carbohydrate bands varied. The ratio between lignin and hemicellulose increased in the wood samples that were exposed to direct and indirect sunlight indicating a decrease in hemicellulose. In the samples that were exposed to direct and indirect sunlight the ratio between lignin and the band at $1425 \mathrm{~cm}^{-1}$ increased slightly, indicating that the crystalline cellulose was slightly affected in the aged samples. A clear decrease in the ratio of lignin and amorphous cellulose at 1375 and $897 \mathrm{~cm}^{-1}$ in the aged samples indicates a stronger effect of heat and sunlight on lignin. In the archaeological sample the hemicellu-1 lose band and the cellulose band at $1375 \mathrm{~cm}^{-1}$ disappeared, and the ratio decreased between the lignin and the two remaining cellulose 2 bands, indicating that the lignin was affected more than the cellulose at these two bands. All the previous results show the gradual 3 decay of archaeological wood during years of exposure to different conditions and restoration treatments, such as bees wax.

\subsection{Cleaning Process}

The cleaning process of any artifact of organic origin can vary from traditional cleaning techniques to the use of laser [37]. These techniques can be applied to remove dust, dirt, writings, etc... But to remove wax in several parts of the panel and inside the cracks and remains of any other adhesives and polymers it was decided to choose a few of the above mentioned wax removal techniques, beginning with mechanical cleaning to remove any solid particles and wax by using fine brushes, scalpel and dental tools. Chemical cleaning was applied by using cotton swabs immersed in ethyl alcohol (80\% in distilled water) to remove some solid particles and writings. Cotton swabs immersed in toluene were used in the cracks to remove wax remains.

Cotton poultices saturated with toluene were used all over the object to extract the largest amount of wax that had been used as a consolidant material.

\subsection{Reshaping and retreatment of the warped panel}

The complete treatment procedure that was applied to retreat the wooden panel was designed according to a strategy that was set according to methods published in previous research and years of conservation experience. Wood warping is due to loss of moisture content in the cell wall of wood, which lead to shrinkage of the panel, therefore the main treatment depended on raising the moisture content, which as a result increases the flexibility of the wood elements. By introducing pressure gradually on the whole deformed panel it was possible to restore it to its original condition [22]. The process was conducted as follows:

- Preparation of a total of 12 wooden sticks with the following dimensions: $3 \times 3 \times 130 \mathrm{~cm}$ (Fig.10a).

- Spraying the wood with a mixture of water and alcohol $(2: 1)$, to raise the wood moisture content gradually.

- Excess water and alcohol were left to evaporate (Fig.10b) to prevent any fungal infesta- 
tion during the period in which the wood would be wrapped with non-stick paper, which was used to avoid any friction between the original panel and the wooden sticks during the reshaping and straightening process of the artifact (Fig.10c).

4- The wooden sticks were arranged perpendicular to each other beneath and above the wrapped wooden artifact, so that any pressure would be distributed evenly during the straightening process (Fig.10d).

5- Four metal clamps were used to gradually exert pressure on the wooden panel (Fig.10e).

6- Retreatment was conducted by consolidation using various concentrations of Klucel $\mathrm{G}$ $0.5 \%-1 \%$ and $2 \%$ dissolved in ethyl alcohol. Microcrystalline cellulose was chosen for filling the gaps and replacing the wax, because its chemical composition was similar to the chemical constituents of wood [38]. A mixture of microcrystalline cellulose and sawdust of a softwood (2:3) mixed with Klucel $\mathrm{G}$ dissolved in ethyl alcohol and water $(1: 1 \mathrm{v} / \mathrm{v})$ were used to fill all cracks in the wooden object.

7- To prevent future warping a wooden background and frame were designed to fit the panel (Fig. 10f).

\section{Conclusion:}

From previous studies it is evident that some of the restoration materials may have a deteriorating effect on the wooden artifacts due to chemical interaction between the wood and the material itself or by its method of application. For example the darkening effect of Paraloid B72 after only 72 hours of exposure to UV [39]. Every material applied in the past needs to be handled differently after understanding its properties, how it was applied and its effects on the artifact.

There may not have been a large variety of polymers and gap fillers used at the Islamic Museum of Art in Cairo as in other museums in Egypt, such as the Egyptian Museum in Tahrir, where different restoration techniques were applied throughout the decades [40]. This fact makes it easier to design a retreatment strategy.

Bees wax, a commonly used material in the past, is a weak penetrating material that leaves a greasy appearance in the wood surface and attracts dust. In the experimental part it was very clear that the color change occurs in the case treated wood, which is partially due to the color change of the bees wax after aging. Bees wax also causes loss in the moisture content of treated wood had a direct effect on the three main wood components; cellulose, hemicellulose and lignin even without ageing, and after aging the wood decayed further.

Having proven that bees wax has a negative effect on wood; it was decided to remove such previous restoration materials from the archaeological wooden panel. In this study traditional methods such as swabs or cotton poultices immersed in solvents (toluene and ethyl alcohol) were applied, because their effect had been previously evaluated. They had no negative effect on the wood in the parts that had been covered with wax and Paraloid B72. Future research needs to be conducted for removing other materials such as PVA emulsions, because the above mentioned techniques would not be effective in cleaning several types of previously applied polymers.

It is therefore recommended to proceed in research dealing with the assessment of different removal techniques such as applying gel systems and enzymes.

The larger the variety of treatments, the more difficult it gets to choose an appropriate technique to remove the material; and the consequences of using new techniques or materials such as gel poultices are currently being evaluated. The comparison between novel and traditional methods would probably give interesting results in future research.

\section{Acknowledgements}

Authors would like to thank all the staff and conservators at the Museum of Islamic art specially Hoda Saleh and Khaled Yehia for their assistance in the conservation of the wooden panel. 


\begin{tabular}{|c|c|c|c|}
\hline$N$. & $\begin{array}{l}\text { Functional } \\
\text { group bands }\end{array}$ & $\begin{array}{l}\text { Standard } \\
\text { Sample }\end{array}$ & $\begin{array}{l}\text { Sample from } \\
\text { Panel }\end{array}$ \\
\hline \multicolumn{4}{|c|}{ Paraloid $\mathrm{B}_{72}$} \\
\hline$A$ & $\mathrm{OH}$ stretching & 3468 & -..-. \\
\hline B & $\mathrm{C}-\mathrm{H}_{2}$ stretching & $2851-2921$ & 2800-3000 \\
\hline C & $\mathrm{C}=\mathrm{O}$ stretching & $1638-1664$ & $1640-1740$ \\
\hline$D$ & $\mathrm{CH}_{2}$ bending & $1380-1424$ & $1350-1480$ \\
\hline$E$ & C-O stretching & 1117 & $1000-1300$ \\
\hline \multicolumn{4}{|c|}{ Beeswax } \\
\hline$A$ & $\mathrm{OH}$ stretching & $344^{8}$ & $3200-3600$ \\
\hline$B$ & $\mathrm{C}-\mathrm{H}_{2}$ stretching & $2884-2918$ & $2800-3000$ \\
\hline C & $\mathrm{C}=\mathrm{O}$ stretching & 1721 & $1700-1750$ \\
\hline$D$ & $\mathrm{CH}_{2}$ bending & 1460 & $1350-1480$ \\
\hline E & $\mathrm{CH}_{2}$ bending & 1380 & $1350-1480$ \\
\hline$F$ & C-O stretching & 1124 & $1000-1300$ \\
\hline G & $\mathrm{CH}_{2}$ torsion & 720 & $700-75^{0}$ \\
\hline \multicolumn{4}{|c|}{ Wood } \\
\hline$A$ & $\mathrm{OH}$ stretching & $3300-3400$ & $343^{8}$ \\
\hline B & $\mathrm{C}-\mathrm{H}_{2}$ stretching & $2800-2900$ & $2841-2921$ \\
\hline C & $\mathrm{C}=\mathrm{O}$ stretching & 1735 & 1641 \\
\hline$D$ & $\mathrm{C}=\mathrm{O}$ stretching & $1630-1710$ & 1508 \\
\hline E & $\mathrm{C}=\mathrm{C}$ stretching & 1508 & 1425 \\
\hline$F$ & CH bending & 1425 & 1375 \\
\hline G & $\mathrm{CH}_{2}$ bending & 1375 & 1164 \\
\hline$H$ & C-O-C stretching & 1163 & 1054 \\
\hline$I$ & C-O stretching & 897 & 896 \\
\hline
\end{tabular}
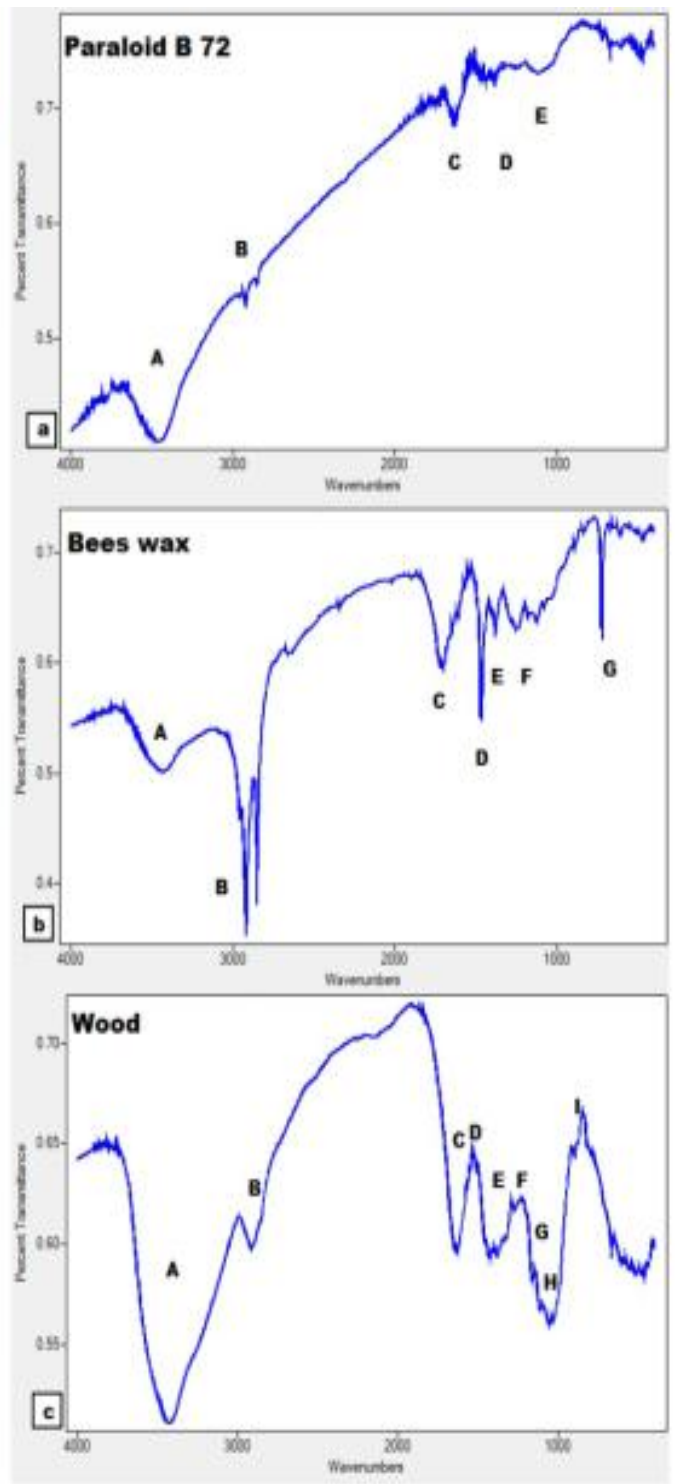

a)

Fig. 8. FTIR spectra of: (a) adhesive and coating layer sample compared with Paraloid B72 functional group bands, (b) wax sample compared with functional groups of bees wax, (c) flaking wood sample 


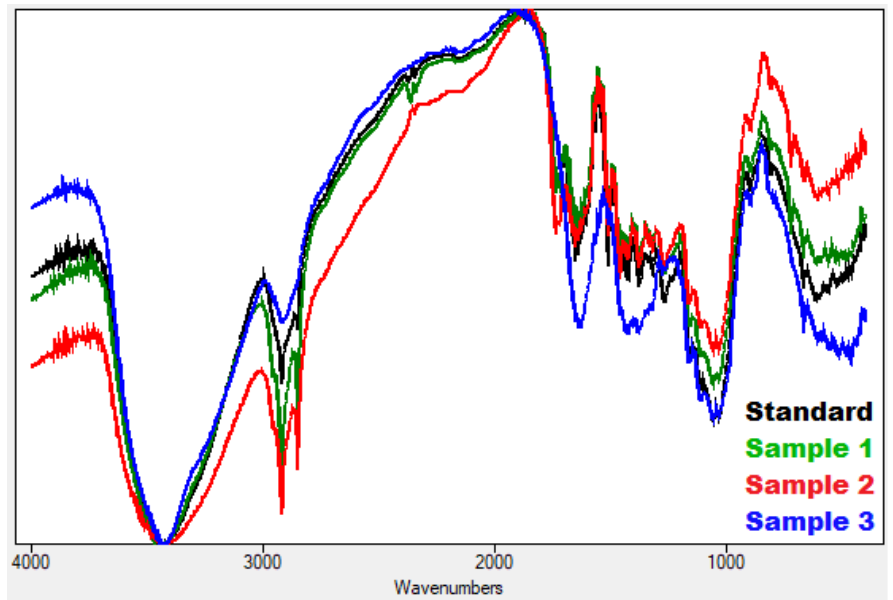

\begin{tabular}{|c|c|c|c|c|}
\hline Sample & $I_{\text {Lignin/1735 }}$ & $I_{\text {Lignin/1425 }}$ & $I_{\text {Lignin/1375 }}$ & $I_{\text {Lignin/897 }}$ \\
\hline Standard & 4.97 & 3.07 & 2.14 & 3.78 \\
\hline Sample 1 & 5.12 & 3.54 & 1.73 & 3.54 \\
\hline Sample 2 & 7.46 & 3.37 & 1.68 & 2.90 \\
\hline Sample 3 & - & 2.25 & - & 1.04 \\
\hline
\end{tabular}

Fig. 9. Calculations of ratios between the lignin and carbohydrate bands within each sample separately indicating the differences between the spectra of the non-aged wood sample (standard), the pine wood that was exposed to indirect sunlight (sample 1), the pine wood that was exposed to direct sunlight (sample 2) and the sample taken from the panel (sample 3)

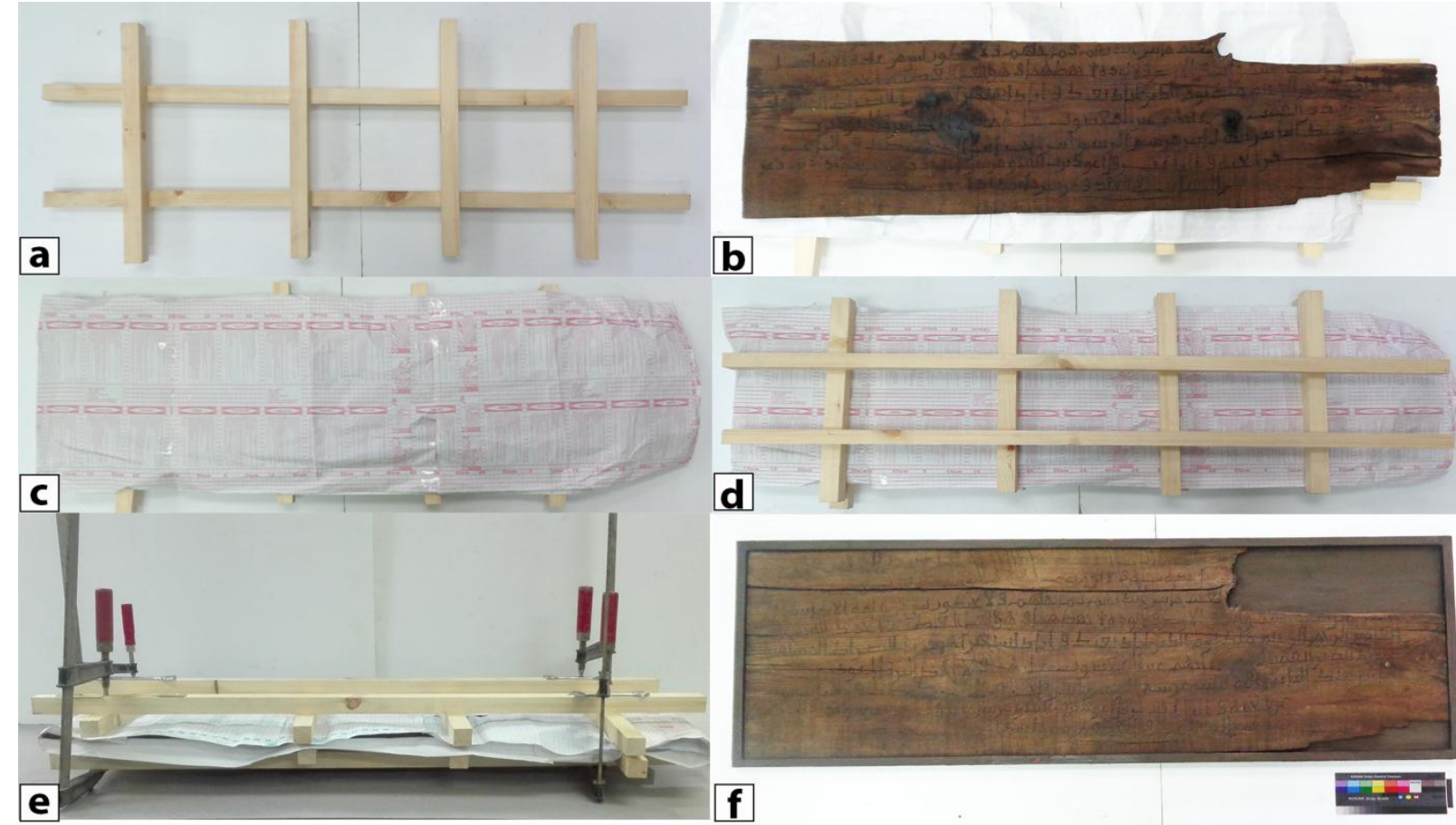

Fig. 10. Reshaping and retreatment (a) Preparation of the wooden sticks, which were arranged perpendicular to each other, (b) Exposure of wood to a mixture of water and alcohol (2:1) to raise the moisture content, (c) Wrapping the object with non-stick paper to avoid any friction, (d) The wrapped wooden panel sandwiched between the wooden sticks, (e) Four metal clamps to exert pressure gradually on the wooden panel, (f) the panel after retreatment. 


\section{References}

1. N. M. N. El Hadidi and S. Darwish, "The use of acids and alkalis in cleaning archaeological wood," 2008. Available: http://scholar.cu.edu.eg/?q=nesrin/files/a cids_and_alkalis.pdf. [Accessed 20179 5].

2. M. Fawzy, A comparative study on the effect of cleaning materials on the chemical composition and mechanical properties of damaged and undamaged wood with the application on chosen archaeological wood. $\mathrm{PhD}$ thesis.[in Arabic, unpublished], Faculty of Archaeology, Cairo University, 2016.

3. S. Hamed, M. Ali and N. M. N. El Hadidi, "Assesment of commonly used cleaning methods on the anatomical structure of archaeological wood," International Journal of Conservation Science, vol.4, No. 2, 2013, pp. 153-160.

4. S. Prati, F. Volpi, R. Fontana, P. Galletti, L. Giorgini, R. Mazzeo, L. Mazzocchetti, C. Samorì and G. Sciutto, "Sustainability in art conservation: a novel bio-based organogel for the cleaning of water sensitive works of art," Pure and Applied Chemistry, vol. 90, no. 2, 2018, pp. 239251.

5. J. Domingues, N. Bonelli, R. Glorgl, E. Fratini and P. Baglionl, "Innovative method for the cleaning of water sensetive artifacts: synthesis and application of highly retentive chemical hydrogels," International Journal of Conservation Science, vol. 4, 2013, pp. 715-722.

6. R. Glorel, M. Baglionl, D. Berti and P. Baglioni, "New Methodologies for the Conservation of Cultural Heritage: Micellar Solutions, Microemulsions, and Hydroxide Nanoparticles," Accounts of Chemical Research, vol. 43, 2009, pp. 695- 704.

7. T. E. o. E. Britannica, "Encyclopaedia Britannica, Museum of Islamic Art," 28 April 2017. [Online]. Available: https://www.britannica.com/topic/museu
m-of-Islamic-Art-museum-Cairo-Egypt. [Accessed 03 May 2020].

8. F. M. Helmi and Y. K. Hefni, "Estimation of Deterioration Aspects of Granitic Columns at the Mosque of Al-Nasir Mohamed Ibn Qalawun,Cairo, Egypt," Advanced Research in Conservation Science, vol. 1, No. 1, 2020, pp. 34-51.

9. N. M. N. El Hadidi and M. M. Fawzy, "A Century of Conservation of Ancient Egyptian Wooden Coffins.," in Second Vatican Coffin Conference- Vatican Museums, 6 - 9 June 2017 - in Press.

10. J. Cronyn, The element of archaeological conservation, London: British library cataloguing, 1990.

11. S. Hamed and N. M. N. El Hadidi, "The Use of SEM-EDX Investigations in Estimating The Penetration Depth of Preparation Layers Within Wood Structure," Advanced Research in Conservation Science, vol. 1, no. 1, 2020, pp. 1-15.

12. S. Bogdanov, "Beeswax: Production, Properties Composition and Control," 16 6 2016. [Online]. Available: https://www.researchgate.net/publication /304012435. [Accessed 201712 15].

13. A. Kaminska, M. Sawczak and M. Ciepeliniski, Colorimetric Study of the Post Processing effect due to Pulsed Laser Cleaning of Paper, Optica Applicata Vol. XXXIV No.1, 2004, pp.121-132.

14. E. Arias, A. Blance, F. Collado-Montero, M. Castillo-Valdivia and D. CampilloGarcia, Conservation of historic book bindings by means of facsimile reproduction: The torres notarial register (1382-1400) in the archive of the royal chancellery of granada, spain, Science and Technology for the Conservation of Cultural Heritage, 2013, pp. 227-230.

15. S. Pentzien, A. Conradi and J. Krüger, The Influence of Paper Type and State of Degradation on Laser Cleaning of Artificially Soiled Paper, Lasers in the Con- 
servation of Artworks VIII, 2011, pp. 5965.

16. K. `Cízzová, K. Vizárová, A. Ház, A. Vykydalová and Z. Cibulková, "Study of the degradation of beeswax taken from a real artefact," Journal of Cultural Heritage, Vol. 37, 2019, p. 103-112.

17. L. X. You, T. M. Cristina and V. M. Anca, "A comparative study on the artificial UV and natural ageing of beeswax and Chinese wax and influence of wax finishing on the ageing of Chinese Ash (Fraxinus mandshurica) wood surfaces," Journal of Photochemistry \& Photobiology, B: Biology, Vol. 201, 2019, pp. 123.

18. N. M. N. El Hadidi, "Decay of softwood in archaeological wooden," Studies in Conservation, Vols. 62 - No:2, no. 00393630, 2017, pp. 83-95.

19. N. M. N. El Hadidi, Treatment and Conservation of Archaeological Wood with the Application on Two Wooden Coffins at the Egyptian Museum. M.A. Thesis. [in Arabic, unpublished], Faculty of Archaeology: Cairo University, 1997.

20. M. Abdel Hady, Treatment and Conservation of Five Various Examples from Wood - Collection Tulunid - Fatimid Periods in the Islamic Museum. Diploma Thesis [in Arabic, unpublished], Faculty of Archaeology: Cairo University, 1980.

21. Y. Akl, A study on the application of wood joints and adhesives - their influence on both wood deterioration and treatment - with the application on selected objects $\mathrm{PhD}$ thesis [in Arabic, unpublished], Faculty of Archaeology: Cairo University, 2017.

22. N. Lokma, Treatment and conservation of warped wood applied on one of the chariots of the King Tut Ankh Amun. Diploma Thesis. [in Arabic, unpublished], Faculty of Archaeology: Cairo University, 1986.
23. H. Ali , Restoration and Conservation of Polychromic Wood - An Applied Study on an Anthropoid Coffin from the Graeco - Roman Period (Deir El Banat Excavation at Fayoum). Diploma Thesis. [in Arabic, unpublished], Faculty of Archaeology: Cairo University, 1987.

24. W. Botros, Scientific study of Reconstructing, Fixing and Restoring the Sanctuaries collection of wood paintings applied on the Angle Sanctuary of St Mina Monastery Fom El Khaleig. PhD thesis. [in Arabic, unpublished], Faculty of Archaeology: Cairo University, 2014.

25. H. Farmakalidis, A. Douvas, I. Karatasios, S. Sotiropoulou, S. Boyatzis, P. Argitis, Y. Chryssoulakis and V. Kilikoglou, "Accelerated Thermal Ageing of Acrylic Copolymers, Cyclohexanone-Based and UreaAldehyde Resins Used in Paintings Conservation," Mediterranean Archaeology and Archaeometry, Vol. 16, 2016, pp. 213-228.

26. C. Conti , J. Striova, I. Aliatis , C. Colombo , M. Greco , E. Possenti , M. Realini , L. Brambilla and G. Zerbi, "Portable Raman versus portable midFTIR reflectance instruments to monitor synthetic treatments used for the conservation of monument surfaces," Analytical and Bioanalytical Chemistry, 2012, pp. 1733-1741.

27. M. Derrick, D. Stulik and J. Landry, Infrared Spectroscopy in Conservation Science, Los Angeles: The Getty Conservation Institute , 1999.

28. G. Crisci, M. La Russa, M. Malagodi and S. Ruffolo, "Consolidation Properties of Regalrez1126 and Paraloid B72 applied to wood," Journal of Culture Heritage, vol. 11, 2010, pp. 304-308.

29. E. Kareem, Study on some chemical change of deteriorated archaeological wood coatings and evalluation of chosen materials and methods of treatment, with 
application on selected example. M.A. thesis [in Arabic, unpublished], Faculty of Archaeology: Cairo University, 2016.

30. A. Adel, Comparative study on the evaluation of natural and synthetic consolidants commonly used in the treatment of local Angiosperm wood with the application on a chosen object. M.A. thesis. [in Arabic, unpublished], Faculty of Archaeology: Cairo University, 2016.

31. S. Koob, "The Use of Paraloid B-72 as an Adhesive Its Application for Archaeological Ceramics and Other Materials," Studies in Conservation, vol. 31, 1986, pp. 7-142.

32. H. Bayoumi, Study on the chemical effect of some consolidants on soft archaeological wood-Application on one archaeological object. M.A. thesis. [in Arabic, unpublished], Faculty of Archaeology: Cairo University, 2018.

33. L. Svečnjak, G. Baranović, M. Vinceković, S. Prđun, D. Bubalo and I. Gajger, "An Approach for Routine Analytical Detection of Beeswax Adulteration Using FTIR-ATR Spectroscopy," Journal of Agicultural Science, Vol. 59, 2014, pp. 37-49.

34. J. Hardin, C. Jones, N. Maness, P. Weckler and J. Dillwith, "Rapid in situ quantification of leaf cuticular wax using FTIR-ATR and DSC," in ASABE Annual International Meeting, 2011.

35. P. Dubey, P. Sharma and V. Kumar, "FTIR and GC-MS spectral datasets of wax from Pinus roxburghii Sarg," Data in Brief, Vol. 15, 2017, pp. 615-622.

36. Y. Zidan, N. M. N. El Hadidi and M. Fawzy, "Examination and analyses of a wooden face at the museum storage at the Faculty of Archaeology, Cairo University," Mediterranean Archaeology \& Archaeometry, Vol.16, 2016, pp. 1-11.

37. G. Abdel-Maksoud, H. Emam and N. Ragab, "From Traditional to Laser
Cleaning Techniques of Parchment Manuscripts: A Review," Advanced Research in Conservation Science, Vol. 1, No. 1, 2020, pp. 52-76.

38. A. Cataldi, F. Deflorian and A. Pegoretti, "Microcrystalline cellulose filled composites for wooden artwork consolidation: Application and physic- mechanical characterization," Materials and Design, Vol. 83, 2015, pp. 611-619.

39. N. M. N. El Hadidi, A Study on some physical, mechanical and chemical changes of deteriorated archaeological wood and it's consolidation, with the application on some selected artifacts at the islamic museum of the Faculty of Archaeology . PhD thesis.[in Arabic, unpublished], Faculty of Archaeology: Cairo University, 2015.

40. N. M. N. El Hadidi, "Changing Research trends in the field of Archaeological wood at the conservation department Faculty of Archaeology- Cairo University," Studies in Conservation, Vol. 60, No. 3, 2015, pp. 143-154. 